\title{
Teaching Research and Practice of the Power \& Electronic Course
}

\author{
Peng Huang ${ }^{1, a}$ and Zhiliang Kang ${ }^{1, b^{*}}$ \\ ${ }^{1}$ College of Mechanical and Electronic Engineering, Sichuan Agricultural University, Ya'an, 625014, \\ China \\ ahpsjdyd@189.cn, 'Zhiliangkang96@163.com \\ *The corresponding author
}

Keywords: Power \& electronic technology; SPOC; Flipped classroom; Teaching research

\begin{abstract}
In order to realize "deep integration" of the information technology and the education, achieve the reform of "students-centered" teaching paradigm, and further explore new teaching modes, our school carried out the teaching reform of flipped classroom by utilizing the self-constructed SPOC resources for power and electronic technology. This paper firstly analyzed all kinds of problem of traditional teaching mode existed in teaching of the power and electronic technology course, proposed taking SPOC + flipped classroom based teaching methods as countermeasures, and then expounded the detailed operation methods of such countermeasures. The result shows that the students think highly of the cognition degree, participation degree and satisfaction degree to SPOC flipped classroom. Comparing to traditional classroom, the students prefer this mode and their abilities of study and practice are improved significantly.
\end{abstract}

\section{Introduction}

The power \& electronic technology is one of important basic undergraduate courses of electrical and automatic majors [1]. Crossing three majors of electronics, electric power science and control theory, the power and electronic technology is widely applied in multiple important fields such as transportation, aerospace communication and household appliances [2] [3]. The power and electronic technology is one of multiple important disciplines with the fastest development and wider and wider application in the field of modern engineering technologies, which makes its mainstay role played in basic undergraduate courses of electrical and automatic majors increasingly emerge. And this course has the features of practicability, engineering-based and comprehensiveness [4]. In order to arouse the students' enthusiasm of study and initiative for independent study, improve the poor cooperation and less interaction between "teaching" and "learning", change the students' previous inefficient study habit and guide them to transform from being weary of studying - interested in study - master methods - learned - know how to learn, our school adopted the innovative integrated "SPOC + flipped classroom" teaching method and achieved favorable teaching results.

\section{Arrangement of Teaching Content}

The content of "the power and electronic technology" focuses on electric and electronic switching devices, regards four kinds of basic transducer and two kinds of control method as basis, four kinds of application as goals, while paying attention to current technological development. In the process of teaching, we explain relevant content of half-controlled devices combining the rectifying circuits, but give detailed instruction on features of full-controlled devices as well as choppers, inverters and transducers with full-controlled devices as components. While compressed thyristor is taught, we also strengthen teaching of full-controlled devices, circuit and control methods. Our school also adds the frontier knowledge of this discipline and introduces their development trend, which is good for developing the good habit of closely following the latest development trend of relevant disciplines for the students. For example, the latest application of in the field of power and electronics such as SVG, power grid harmonic suppression technology, high voltage DC transmission technology, high voltage 
transducer and matrix AC-AC convertor are introduced to the students as supplementary knowledge and expansion. Moreover, the application around the student's life such as electronic ballast and solar power generation should be inserted into teaching of appropriate chapters for enhancing the students' perceptual knowledge of the power and electronic technology around them.

\section{The Teaching Method of Integrated "SPOC + Flipped Classroom"}

The special characters of seeking innovation and change of the students of the generation after 90s are basic preconditions for performing the teaching work well. The most of students now we face to are the generation after 90s, they are tired of or even dislike the traditional teaching methods, but they are fond of the Internet, new technologies and new teaching methods and extremely thirst for mastering them. On this basis, we adopt the teaching method of integrated "SPOC + flipped classroom" with the objective of fully arousing the students' interest and enthusiasm for learning the power and electronic technology course.

Application of SPOC. SPOC is short for Small Private On-line Course [6]. Adopting specific teaching design thought and applying the multi-media technology, we pertinently explain a video with regard to a knowledge point within a few minutes. The content taught by SPOC are knowledge points and segments which are not limited to detailed teaching content such as interpretation of teaching materials, thorough explanation of question types and summing up items of examination, but also include knowledge explanation and presentation with respect to methodology such as imparting of study methods and introduction of teaching experience. SPOC is not only suitable for spreading knowledge in the times of mobile study, but also meets students' requirements of personalized and in-depth study [7] [8].

SPOC plays different roles in preparation for new lessons [9]. First of all, according to the students' knowledge basis and the cohesion knowledge required for new knowledge, corresponding SPOC videos are provided to the students before teaching new lessons for the students to watch in extracurricular time and make preparation for the new lessons. Second, the common teaching method for introducing new lessons is that the teachers design novel questions on the basis of the knowledge points of the new lessons in order to attract the students' attention and pave the way for teaching new lessons. Make SPOC according to this teaching method, and let the students watch this video after beginning class and going over the previous lesson. And this process is taken as a novel start for learning new lessons. Finally, the teachers' direction on key and difficult points in the new lessons and guidance on exploring rules of typical examples can also be made into SPOC for the students to watch after they explore independently or cooperatively.

The knowledge points of the course of power and electronic technology are both numerous and hard, and there are also many output wave forms. It would be very difficult for the students if it lets them prepare by simply reading book. According to above characteristics of SPOC, when the teaches prepare lesson, they shall make corresponding videos by themselves or research and buy them from Internet, and then release them on the SPOC platform for the students to warm up for the new content, attracting their attention on study and achieving the effect of preparation before class.

The teachers shall utilize the SPOC platform to cut and adjust the resources according to teaching progress and syllabus. Allocation of credit hours and chapter sequence shall be corresponded to the syllabus, and release of course information and setting of key time nodes are done by teachers according to their respective teaching requirements. The teachers shall also maintain the forum and release the materials to be shared with the students at any time. If necessary, the teachers may make special videos and upload to the SPOC platform aiming at some contents according to the students' cognitive level in order to provide more pertinent study resources for the students. The teachers can also master the on-line study data of the students through big data of the SPOC platform so as to guide the students to study efficiently at any time.

SPOC Flipped Classroom Based Teaching. The SPOC flipped classroom based teaching is divided into three links of before-class, in-class and after-class [10]. The course teaching team designs 
before-class task sheet according to SPOC resources for guiding and helping the students to carry out independent study. The proportion of each part of the task sheet is constantly adjusted and the training emphasis of students' abilities is constantly changing in the whole teaching process so as to ensure the teaching design is student-oriented and achieve the goal of guiding the students to study efficiently and independently before class and promoting their abilities.

The teachers shall analyze the students' condition, content and difficulty of each class and estimate the students' acceptance condition before giving class so as to determine the flipping degree and teaching method of each class, and then design classroom knowledge point route and ability training goals on such basis. The overall design shall be echo with the before-class task table and have the same stage.

In the flipped classroom, the status of teacher and student is changed. The teachers are responsible for hosting and guiding conduct of content, supplementing and summarizing incomplete and incorrect presentation of the students, coordinating and controlling the study time of each part as well as judging the students' study result; the students should combine gain and questions from preparation before class to deeply understand the knowledge on the basis of self thinking and the cooperative study mode. The collision of the teachers' and students' thinking in the process of cooperation can make them have the sense of identity so as to form a brand new way for communication. It is conducive to realizing the good study atmosphere that good students help backward students that the students are organized to study in the form of team; mutual evaluation among teams and quick answer will make the teams compete with one another and promote efficiency and abilities; teamwork awareness, team cooperation ability and competition awareness of the students are virtually cultivated and promoted.

In order to guarantee the teaching effects and realize training of students' abilities, the after-class link includes two major tasks: (1) Assign homework according to the content of lesson for enhancing the knowledge; (2) Require the students to summarize relationship between knowledge points on the basis of the content of the previous class.

\section{Effects of Implementation}

The SPOC based flipped classroom teaching has been implemented for a year in pilot class and achieved the following significant results:

(1) The students of the pilot class achieved remarkable progresses, more and more students perform preparation before class following the teachers' requirements; the students can concentrate their mind in class and have keen interest, the class atmosphere is greatly improved; and the most of the students are gradually able to think independently and developed the habit of that from being lax in thinking and having no ideal on how to start at the very beginning.

(2) The academic records are much better than that of parallel classes. We performed data analysis to all students' scores of final examination of the fall semester 2015, the results are shown as Table 1 .

According to Table 1, when the maximum score is 100, the average score of the pilot class is 9 higher than that of traditional class and the number of students failed in the exam is $15 \%$ lower than that of the traditional class, which indicates that the pilot class is indeed effective in the new teaching mode.

Table 1 Comparison of examination scores

\begin{tabular}{|c|c|c|}
\hline & Pilot class 80 students & Traditional class 86 students \\
\hline Ave. scores & 75 & 66 \\
\hline Rate of fail & $27 \%$ & $42 \%$ \\
\hline
\end{tabular}

(3) In order to accurately understand the students' evaluation and thought on this brand new teaching mode, we released anonymous questionnaires to all students in the middle-term of this semester. This questionnaire was classified into four parts, i.e. extracurricular learning condition, class condition, promotion of students' abilities and students' message, with totally 25 questions. A part of questionnaire results are now excerpted and analyzed as shown in Fig. 1. 



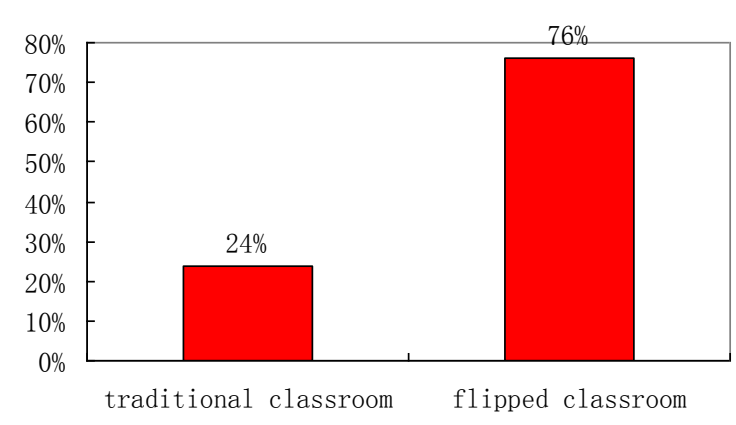

(c) selection of teaching mode



(d) Ability Promoted

Figure 1. Results of student questionnaire investigation

Fig. 1 (a) shows that the students who "prepare before class" and "prepare before class in the most of time" are nearly $41 \%$, which is greatly improved comparing to the most of students do not prepare before class, review after class and study outside classroom previously. With carrying on of the course, more and more students will be engaged in study outside classroom. This shows that the goal of converting passive study to initiative study that we expected is preliminarily realized.

Fig. 1 (b) shows that the students' interest of study in classroom is substantially promoted over traditional classroom; and this brand new form of study is accepted by the most of the students.

Fig. 1 (c) shows the students' selection of teaching mode. Up to $76 \%$ students like and choose the flipped classroom. Only $24 \%$ students like the traditional teaching mode.

Fig. 1 (d) gives the ability promotion of the students. It can see that nearly $76 \%$ students believe their abilities are promoted. This shows that the students highly recognize the promotion of their abilities and also proves that our teaching reform is fruitful. And the objective of reform that changing teaching from knowledge transfer to ability training is gradually realizing.

\section{Conclusion}

The SPOC + flipped classroom based teaching mode enriched the teaching modes under the background of SPOC, deeply combined the information technology and the education, integrated three stages of before-class, in-class and after-class, make the students go through the process from knowledge acquiring, knowledge internalization to knowledge sublimation, truly realized reform of "student-centered" teaching paradigm, and it was high appraised by students in course survey and feedback in the end of semester. However, the implementation of SPOC + flipped classroom based teaching shall be with condition of all aspects, so how to effectively implement and promote and guarantee the expected teaching results is an issue worth to be thought deeper. 


\section{Acknowledgements}

The authors gratefully acknowledge the supported by the educational reform project of Sichuan Agricultural University (grant number: x2015025).

\section{References}

[1] Ran Jianguang, Research on power electronic technology based on the modern background [J], Electronic Test,2016,05:147-148.

[2] Geng Guangfei,Yang Jianhua, Tang Wei, Comparison and reflection on international electrical engineering curriclum systems [J], Journal of EEE, 2016,01:53-56.

[3] Luo Meimei, Tang Jie, Liu Baiyang, The Exploration of power electronic technology reform based on "1411" knowledge module [J]. China Modern Educational Equipment, 2016,09:90-92.

[4] Zhang Wenwei, Exploration \& practice on construction of the "Power \& Electronic Technology" course [J], China Electric Power Education, 2012(6):66-67.

[5] Tang Lin, Lin Li, Liu Jiafang, Li Haina, The exploration and practice of the research-based teaching for power electronics technology course [J], 2011,03:76-78.

[6] Zhang Qiang, Zhang Haifeng, Tang Yan, Implementation of lipped classroom teaching mode based on SPOC in Circuit Theory course [J], 2016,01:187-190+194.

[7] Xiang Fangli, Research on the teaching reform of flipped classroom in higher vocational colleges based on SPOC [J], 2016,02:102-104.

[8] Xiu Juan, Liu Wei. Thought of Reform of the "Power \& Electronic Technology" Course [J], Journal of Electrical \& Electronic Education, 2009(6):30-31.

[9] Xue Yun, Zheng Li, Exploration and Reflection of SPOC: Based Teaching Model in Flipped Classroom [J], 2016,05:132-137.

[10]Zeng Mingxing, Li Guiping, Zhou Qingping, From MOOC to SPOC: Construction of a Deep Learning Model [J], China Educational Technology, 2015,11:28-34+53. 